\title{
Foley catheter through a colovesical fistula: an unusual method of diagnosis
}

\author{
Khilan Pindoria, ${ }^{1}$ Ashraf Reyad, ${ }^{1}$ Yassar Youssef ${ }^{1,2}$
}

${ }^{1}$ Department of Surgery, Sinai Hospital of Baltimore, Baltimore, Maryland, USA ${ }^{2}$ Department of General Surgery, Johns Hopkins Hospital, Baltimore, Maryland, USA

\section{Correspondence to} Dr Yassar Youssef, yassaryoussef@hotmail.com

Accepted 17 April 2014
CrossMark

To cite: Pindoria $\mathrm{K}$, Reyad A, Youssef Y. BMJ Case Rep Published online: [please include Day Month Year] doi:10.1136/bcr-2014204968

\section{DESCRIPTION}

An 89-year-old woman with a known history of diverticulitis presented to our emergency department (ED) with a few days' history of haematochezia. She had decided to seek medical help after having a severe episode of bloody stool and feeling dizzy. Her vital signs were normal, and her physical examination disclosed mild left lower quadrant tenderness but no peritoneal signs. Given her presentation, she was resuscitated according to protocol, which included the insertion of a Foley catheter by the ED staff. The patient was then taken to the radiology department for a CT scan of the abdomen and pelvis. Afterwards she was brought back to her ED room, where it was noticed that her urine bag contained a dark green, stool-like thick fluid. Upon further examination, the bag did indeed contain loose stool but had no evidence of blood. When her CT scan was reviewed, it was obvious that the patient had a large colovesical fistula which resulted from her diverticular disease, manifested by the passage of the Foley catheter into the colon (figure 1) through the fistulous tract (figure 2). As the patient was not septic and was stable haemodynamically, the Foley's balloon was deflated and the catheter was removed completely. A detailed past medical history revealed that the patient had been treated three times in the past 2 years for urinary

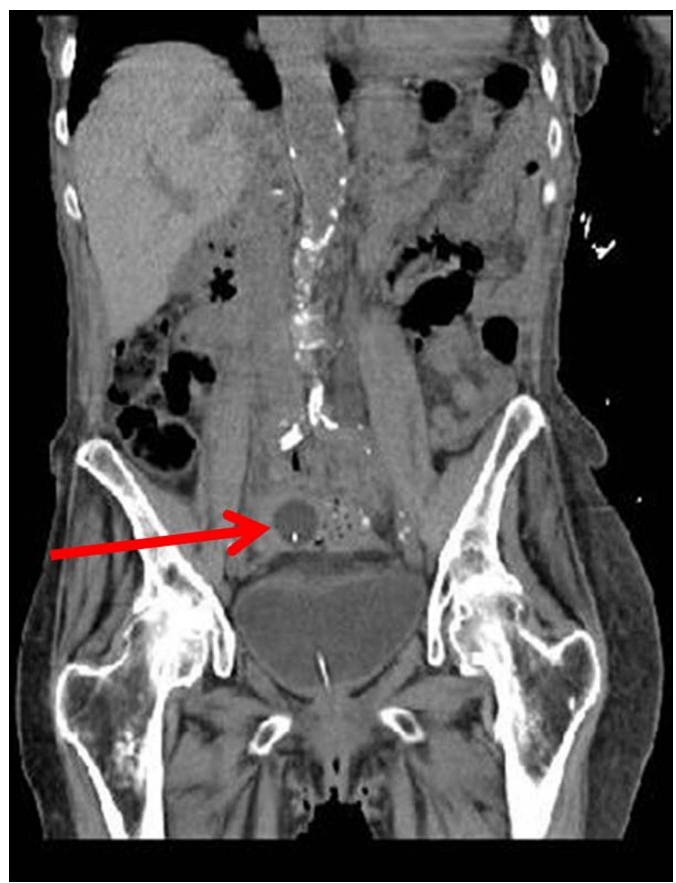

Figure 1 Passage of the Foley catheter through a large colovesical fistula into the colon. The tip of the catheter is indicated by the arrow as visualised in the colon.

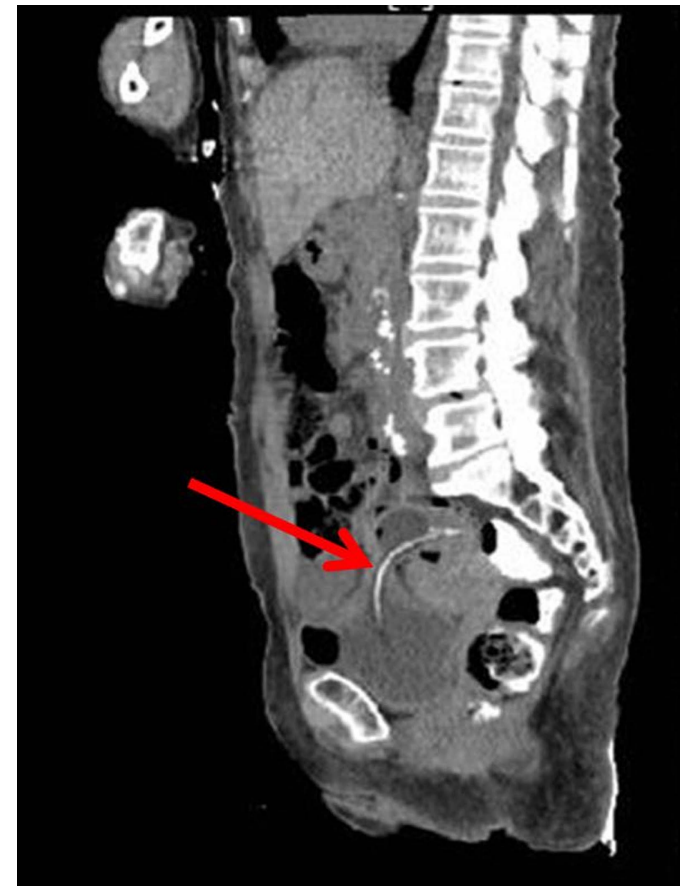

Figure 2 Passage of the Foley catheter from the bladder through the fistulous tract into the colon as indicated by the arrow.

tract infections. The patient was admitted and a cystoscopy revealed the site of the fistulous tract. The patient was educated about the natural history of this disease, declined any further intervention and was discharged 2 days after her admission.

Colovesical fistula, a communication between the colon and the urinary bladder, is a known but rare complication of diverticular disease. It can occur secondary to other pathology, including colon or bladder cancer, trauma and Crohn's disease, but the most common reported incidence is in patients with complicated diverticular disease. ${ }^{1}$ It is more common in males, probably secondary to the interposition of the uterus between the colon and the bladder; a hysterectomy had been carried out in almost half of reported cases in females. This complication also tends to occur in the elderly, with most patients being over 70 years of age.

Urinary tract infection is a very common presentation and is seen in about $80 \%$ of patients. Pneumaturia (passage of gas or air in urine) and fecaluria (passage of stool in urine), while potentially difficult for patients to detect, are also common presentations, reported in $50-100 \%$ of this population. ${ }^{2}$

Diagnosis is based on the clinical history in addition to radiological and diagnostic procedures. 
CT scan is the most sensitive and commonly used imaging study, capable of demonstrating air or contrast material in the bladder, localised thickening of the bladder wall, or an extraluminal gascontaining mass adjacent to the bladder. Cystoscopy is probably the most reliable and sensitive diagnostic procedure, allowing accurate diagnosis and localisation and also biopsy to rule out malignancy. A colonoscopy is also helpful, not for detecting the fistula itself but for assessing the colon status and possible aetiology of the fistula. ${ }^{1}$

Historically, and even recently, surgery was recommended for all patients diagnosed with a colovesical fistula, mainly due to

\section{Learning points}

- Colovesical fistula, a communication between the colon and the urinary bladder, is a known but rare complication of diverticular disease but can occur secondary to other pathology.

- Colovesical fistula is more common in males and in elderly patients.

- Urinary tract infection is seen in about $80 \%$ of patients, while pneumaturia and fecaluria are reported in $50-100 \%$ of patients.

- Diagnosis is based on the clinical history in addition to radiological and diagnostic procedures, including CT scan, cystoscopy and colonoscopy.

- Surgery is no longer routinely recommended as most patients are elderly with multiple co-morbidities. the fear of renal failure and sepsis. ${ }^{2}$ Recently, this treatment has been challenged. Many have observed that patients who refused surgery or were unfit for a surgical procedure at the time of diagnosis, did relatively well compared to those who had surgical intervention. ${ }^{3}$ Based on such observation, the fact that most patients with colovesical fistula are elderly with multiple co-morbidities, and the knowledge that even surgical management may be unsatisfactory with a complication rate as high as $45 \%$, it seems that offering supportive treatment only is a viable option with surgical intervention reserved for complications including sepsis and severe recurrent urinary tract infections or for improvement of quality of life as determined by the patient. A 5-year follow-up study of patients who had surgical intervention showed that most of the patients died within few years after the procedure from unrelated causes. This study also indicates that these are high-risk patients and questions the need for surgical intervention. ${ }^{4}$

Contributors KP: collected the images, and wrote and edited the article; AR: collected the data, and wrote and edited the article; YY: edited the article.

\section{Competing interests None.}

Patient consent Obtained.

Provenance and peer review Not commissioned; externally peer reviewed.

\section{REFERENCES}

1 Najjar SF, Jamal MK, Savas JF, et al. The spectrum of colovesical fistula and diagnostic paradigm. Am J Surg 2004;188:617-21.

2 Garcea G, Majid I, Sutton CD, et al. Diagnosis and management of colovesical fistulae; six-year experience of 90 consecutive cases. Colorectal Dis 2005;8:347-52.

3 Solkar MH, Forshaw MJ, Sankararajah D, et al. Colovesical fistula-is a surgical approach always justified? Colorectal Dis 2005;7:467-71.

4 Walker KG, Anderson JH, Iskander N, et al. Colonic resection for colovesical fistula: 5-year follow-up. Colorectal Dis 2002;4:270-74.

Copyright 2014 BMJ Publishing Group. All rights reserved. For permission to reuse any of this content visit http://group.bmj.com/group/rights-licensing/permissions.

BMJ Case Report Fellows may re-use this article for personal use and teaching without any further permission.

Become a Fellow of BMJ Case Reports today and you can:

- Submit as many cases as you like

- Enjoy fast sympathetic peer review and rapid publication of accepted articles

- Access all the published articles

- Re-use any of the published material for personal use and teaching without further permission

For information on Institutional Fellowships contact consortiasales@bmjgroup.com

Visit casereports.bmj.com for more articles like this and to become a Fellow 